\title{
Adult patients hospitalised for inaugural diabetes in Bordeaux during 1996-1997 and 2008-2009: a changing scene
}

\author{
Sophie Salandini ${ }^{1 *}$, Vincent Rigalleau ${ }^{1}$, Concepcion Gonzalez ${ }^{1}$, Christelle Raffaitin ${ }^{1}$, Agnès Georges ${ }^{2}$, Jean-Benoit Corcuff ${ }^{2}$ and Henri Gin ${ }^{1}$ \\ Correspondence: sophiesalandini@hotmail.fr \\ ${ }^{1}$ Nutrition-Diabétologie and ${ }^{2}$ Nuclear Medicine, Hôpital Haut-Lévêque, Avenue de Magellan, 33600 Pessac, France.
}

\begin{abstract}
Objectives: Are the adult patients hospitalized for new-onset diabetes changing?

Research Design and Methods: The patients were identified in the registry of admissions of the Nutrition-Diabetology unit of the Universitary Hospital of Bordeaux, France, for the years 1996-1997 and 2008-2009, and compared by ANOVA and Chi-2, before and after being categorized according to the presence of antiGAD antibodies.

Results: One hundred and fifty-three patients (106 men, 51 antiGAD+) were admitted: 61 during 1996-1997 and 92 during 20082009, with similar clinical presentations: $-6.7 \pm 5.8 \mathrm{~kg}$ weight loss, plasma glucose $20 \pm 16 \mathrm{mmol} / \mathrm{L}, \mathrm{HbA1C} 11.9 \pm 2.5 \%$. The $2008-2009$ patients were younger ( $41 \pm 16$ yrs vs 1996-1997: 47 \pm 18 , p<0.05), due to younger antiGAD+ patients (28 \pm 9 yrs vs 1996-1997: 38 \pm 17 , $\mathrm{p}<0.05)$. The antiGAD- 2008-2009 patients were heavier $(78.1 \pm 24.1 \mathrm{~kg}$ vs 1996-1997: 66.1 $\pm 12.1 \mathrm{p}<0.05)$, and tended to more frequently consume sugar-sweetened beverages ( $43 \%$ vs $1996-1997: 22 \%, \mathrm{p}=0.059)$. The treatment had similar effects on both periods: capillary glucose at discharge $138 \pm 38 \mathrm{mg} / \mathrm{dL}, \mathrm{HbA1C} 7.2 \pm 1.7 \%$ four months later, but the hospitalizations were $25 \%$ shorter on 2008 2009 (7.5 \pm 2.7 days vs 1996-1997: 9.9 $\pm 5.4, \mathrm{p}<0.005)$. Discharges without insulin were less frequent on 2008-2009 (20\% vs 1996-1997: $36 \%, \mathrm{p}<0.05)$, concerning very heavier patients $(93.2 \pm 28.8 \mathrm{~kg}$ vs $76.9 \pm 18.0, \mathrm{p}<0.05)$.

Conclusions: Fifty percent more adult patients were hospitalized for inaugural diabetes during 2008-2009. The proportion of antiGAD+ patients did not change but they were $10 \mathrm{yrs}$ younger, whereas the antiGAD- patients were $12 \mathrm{~kg}$ heavier. The duration of hospitalization was reduced by $-25 \%$, with similar HbA1C 4 months later, but less patients were discharged without insulin.
\end{abstract}

Keywords: diabetes, onset, adult, obesity, antiGAD

\section{Introduction}

Diabetes is a chronic disease, requiring outpatient care in most cases. Newly diagnosed cases may however require an hospitalization, at least for children and adolescents, and substantial and chronic poor metabolic control needing etiological explorations may lead to admissions in adults [1]. In France, the discovery of a new-onset diabetes with frank hyperglycemia and loss of weight in an adult, leads to presume type 1 diabetes for many general practitioners, which is a common indication to hospitalize the patient for the initiation of insulin.

The rising incidence of diabetes, type 2 but also type 1 [2], may impact the presentation of these patients. Are these hospitalizations more frequent ? Does type 1 diabetes (T1D) occur earlier in adults, as in children [3]? What is the impact of the obesity epidemic on the body weight and insulin dosages of these patients? To answer these questions, we compared the clinical presentations of adults admitted for new-onset diabetes in our clinical ward (Nutrition-Diabétologie, the main location for hospitalization for diabetes in Bordeaux, France) during the 1996-1997 and 2008-2009 years. The comparisons were repeated after categorizing the patients according to the presence of anti-GAD antibodies, and in the especial group of patients who could be discharged without initiating insulin therapy.

\section{Subjects and Methods}

The inclusions were retrospectively performed by systematic examination of the register of admissions of the NutritionDiabetology Unit of the Centre Hospitalier Universitaire of Bordeaux, for the years 1996-1997 and 2008-2009. This clinical ward receives $\sim 5$ adult patients with diabetes per day, and $\sim 1$ on saturdays and sundays The patients below 14 years age are oriented to the Pediatry department. The subjects were included if the indication mentioned for admission was a new-onset diabetes ("Diabète Inaugural"), according to the phone call of the General Practitioner who addressed the patient. Pregnant women, and previously known diabetes were excluded. 
Salandini et al. Journal of Diabetes Research and Clinical Metabolism 2012,

The patients were all interviewed and physically examined; an intercurrent pathology that might have exacerbated the hyperglycaemia was researched. Due to the frequency and reversibility of these causes, we systematically asked whether the patients had any treatment with corticosteroids during the months before admission, and we also systematically asked whether they compensated their polyuria with sweetened beverages (fruit juice, sodas, syrup). The durations of clinical signs (mainly polyuria), the weight loss during the previous three months, and the maximal body weight during life, were also recorded.

The following biological parameters were measured: fasting plasma glucose and C-peptide (before any insulin administration), HbA1C, ketonuria (strip), anti-GAD antibodies. Autoantibody AntiGAD were detected by AntiGAD Technique RIA Brahms in $1996(0,9 \mathrm{UI} / \mathrm{mL}$ was used as the limit of positivity) and by Anti GAD Technique RIA Cis Bio in 2008 $(0,33 \mathrm{nmol} / \mathrm{L}$ as the limit of positivity). Concerning C peptide we used C peptide Technique RIA-Coat Mallinkrodt in 1996 $(0,33-0,73 \mathrm{nmol} / \mathrm{L})$ and $C$ peptide technique $C$ is bio IRMA in $2008(0,34-1,17 \mathrm{nmol} / \mathrm{L})$. Other biological and radiological exams were performed according to the clinical findings.

All the patients had dietary advices, they learned selfcapillary glucose monitoring, and most of them began on insulin therapy, unless the diagnosis of type 2 diabetes with poor control due to dietary errors, or resolved intercurrent disease, was presumed. In all cases the insulin dose and the capillary glucose level on the day of discharge were recorded. The patients had a follow-up visit 4 months later, their body weight and $\mathrm{HbA} 1 \mathrm{C}$ were then recorded.

The results are expressed as mean \pm SD. The comparisons between the two periods (1996-1997 and 2008-2009), and between groups of patients (anti-GAD+ vs anti-GAD-, discharged with insulin vs without) were performed by ANOVA and unpaired $t$ tests for continuous variables, and Chi-2 for non-continuous. We also performed a regression analysis to search which determinants were associated to the two main characteristics that changed between both periods: the age for anti-GAD+ subjects, and the body weight for antiGAD-subjects. $P<0.05$ was considered as significant. All the analysis were performed using a SPSS software, version 10.0.

\section{Results}

\section{New-onset diabetes}

One hundred fifty three patients were admitted for new-onset diabetes: 61 during 1996-1997 and 92 during 2008-2009. As summarised in the Table 1, the clinical signs that led to the hospitalization did not differ between the two periods: -6.5 $\mathrm{kg}$ weight loss during the previous three months, and frank hyperglycaemia with $\sim 12 \% \mathrm{HbA} 1 \mathrm{C}$. The relative number of patients with anti-GAD+ and the C-peptide levels also did not differ, which suggests that the proportion of both types of diabetes did not dramatically change between the two periods. The treatment were similarly effective, as reflected by the fasting capillary glucose levels on the day of discharge $(\sim 140 \mathrm{mg} / \mathrm{dL})$, and similar $\sim 7.2 \% \mathrm{HbA} 1 \mathrm{C}$ four months later, although the duration of hospitalisation was $25 \%$ less during 2008-2009 ( $p<0.005)$. The main difference between the two periods was that the patients were $\sim 6$ years younger $(p<0.05)$ during 2008-2009. They were also $\sim 5 \mathrm{~kg}$ heavier, but this did not reach significance $(p=0.12)$. The proportion of patients with identified intercurrent diseases, or corticosteroid use, did not change, whereas there was a tendency for more frequent consumption of sweetened beverages during 2008-2009. Of note, after excluding the 11 patients who had serious intercurrent diseases altering body weight and appetite ( 6 cancers, 4 chronic pancreatitis, 1 liver transplantation), the more frequent consumption of sweetened beverages and the higher body weight 4 months after discharge were both significant $(p<0.05)$.

\section{Patients with positive anti-GAD antibodies}

Fifty-one patients (34 men) had positive anti-GAD antibodies. As compared to patients with negative anti-GAD, they were younger ( $32 \pm 13$ vs $46 \pm 15 \mathrm{yrs} ; \mathrm{p}<0.001$ ), lighter (BMI $25.6 \pm 4.6$ vs $29.4 \pm 6.3 ; p<0.001)$, more acutely hyperglycemic $(24 \pm 17$ vs $17 \pm 9 \mathrm{mmol} / \mathrm{L} ; \mathrm{p}<0.01-\mathrm{HbA} 1 \mathrm{C}$ did not differ) and ketonuric $(1.8 \pm 1.2$ vs $0.6 \pm 0.9+; p<0.001)$, they had lower $C$-peptide $(0.48 \pm 0 ; 55$ vs $1.01 \pm 0.82 \mathrm{nmol} / \mathrm{L} ; \mathrm{p}<0.001)$, and they required higher insulin doses ( $45 \pm 26$ vs $25 \pm 24 \mathrm{U} /$ day; $p<0.001$ ).

The comparison between both periods in the patients with positive anti-GAD is summarised in the Table 2 . The main finding was that the patients were 10 years younger $(p<0.05)$ during 2008-2009. The age of patients with antiGAD+ diabetes was positively correlated to the $\mathrm{BMI}$ at admission $(r=0.52 ; p<0.001)$, and also (with lower $r)$ to the body weight,

Table 1. Characteristics and outcome of the patients hospitalized for new-onset diabetes, 1996-1997 vs 2008-2009.

\begin{tabular}{lccc}
\hline & $\mathbf{1 9 9 6 - 1 9 9 7}$ & $\mathbf{2 0 0 8 - 2 0 0 9}$ & $\mathbf{p}$ \\
\hline $\mathrm{n}$ & 61 & 92 & \\
Men/women & $39 / 22$ & $67 / 25$ & $\mathrm{NS}$ \\
Age (yrs) & $47 \pm 18$ & $41 \pm 16$ & 0.03 \\
Body weight (kg) & $67.9 \pm 17.5$ & $72.8 \pm 20.7$ & $\mathrm{NS}$ \\
BMI(kg/m $\left.{ }^{2}\right)$ & $24.0 \pm 5.6$ & $25.1 \pm 6.7$ & $\mathrm{NS}$ \\
Glycaemia (mmol/L) & $21 \pm 18$ & $19 \pm 15$ & $\mathrm{NS}$ \\
HbA1C (\%) & $11.8 \pm 2.8$ & $12.0 \pm 2.3$ & $\mathrm{NS}$ \\
Weight loss (kg/3months) & $-6.7 \pm 4.6$ & $-6.6 \pm 6.5$ & $\mathrm{NS}$ \\
Intercurrent disease (n) & 24 & 34 & $\mathrm{NS}$ \\
Corticosteroid use(n) & 9 & 8 & $\mathrm{NS}$ \\
Sweetened beverages (n) & 14 & 35 & $\mathrm{NS}(0.054)$ \\
Anti-GAD + (n) & 18 & 33 & $\mathrm{NS}$ \\
Serum C-peptide (nmol/L) & $1.08 \pm 1.00$ & $0.81 \pm 0.69$ & $\mathrm{NS}$ \\
Duration of hospitalization (d) & $9.9 \pm 5.4$ & $7.5 \pm 2.7$ & 0.001 \\
Capillary glucose level at discharge & $142 \pm 38$ & $136 \pm 38$ & $\mathrm{NS}$ \\
(mg/dL) & $25 \pm 24$ & $36 \pm 27$ & 0.012 \\
Daily insulin dose at discharge (U) & $71.1 \pm 17.1$ & $77.1 \pm 17.1$ & NS (0.09) \\
Body weight 4 months later (kg) & $7.1 \pm 1.9$ & $7.3 \pm 1.5$ & NS \\
HbA1C 4 months later (\%) & & &
\end{tabular}


Salandini et al. Journal of Diabetes Research and Clinical Metabolism 2012,

http://www.hoajonline.com/journals/pdf/2050-0866-1-12.pdf

maximal BMI during life, maximal body weight during life, to the C-peptide level and to the dose of insulin at discharge.

\section{Patients with negative anti-GAD antibodies}

In 77 patients, anti-GAD were dosed and negative. The comparison between both periods in the patients with negative anti-GAD is summarised in the Table 3 . The age of onset did not differ $(p=0.50)$, whereas the main difference was a $+12 \mathrm{~kg}$ body weight during 2008-2009 $(p<0.05)$. By contrast to the relationship in patients with positive antiGAD antibodies, the BMI did not correlate to the age for anti-GAD negative patients, but it was positively correlated to the insulin dose at discharge $(r=0.32 ; p=0.005)$ and to the C-peptide level $(r=0.30 ; p=0.01)$.

\section{Patients discharged without insulin therapy}

Forty-one patients (31 men) were discharged without initiation of insulin therapy. As compared to others, they were older $(52 \pm 15$ vs $40 \pm 17$ yrs; $p<0.001)$, heavier ( $84 \pm 24$ vs $66 \pm 15 \mathrm{~kg}$; $\mathrm{p}<0.001)$, less hyperglycemic $(15.4 \pm 6.1 \mathrm{vs} 22.0 \pm 15.3 \mathrm{mmol} / \mathrm{L}$; $\mathrm{p}<0.05$, HbA1C: $10.8 \pm 2.1$ vs $12.3 \pm 2.5 ; \mathrm{p}<0.005)$, and less ketonuric $(0.6 \pm 0.8$ vs $1.2 \pm 1.3+; p<0.05)$, with higher $C$-peptide $(1.39 \pm 0.41$ vs $0.72 \pm 0.74 \mathrm{nmol} / \mathrm{L} ; \mathrm{p}<0.001)$. Four only had positive anti-GAD (vs 47 in the insulin-treated group, $p<0.001$ ). The duration of their hospitalization was shorter $(7.2 \pm 3.5$ vs $8.9 \pm 4.3$ days; $p<0.05)$, with similar capillary glucose levels at discharge (132 \pm 27 vs $141 \pm 41 \mathrm{mg} / \mathrm{dL} ; \mathrm{NS})$.

As shown in the Table 4, the findings in the negative antiGAD group were magnified in these non-insulin treated patients: no significant difference for age (1996-97: 54 \pm 15 , 2008-09: $50 \pm 15$ yrs; $p=0.42)$ but a $+16 \mathrm{~kg}$ body weight in 20082009 (1996-97: 77 $\pm 18,2008-09$ : 93 \pm 28 kg; $p<0.05$ ).

Table 2. Characteristics and outcome of the patients hospitalized for new-onset diabetes, 1996-1997 vs 2008-2009. Patients with positive anti-GAD antibodies.

\begin{tabular}{lccc}
\hline & $\mathbf{1 9 9 6 - 1 9 9 7}$ & $\mathbf{2 0 0 8 - 2 0 0 9}$ & $\mathbf{p}$ \\
\hline $\mathrm{n}$ & 18 & 33 & \\
Men/women & $9 / 9$ & $25 / 8$ & $\mathrm{NS}$ \\
Age (yrs) & $38 \pm 17$ & $28 \pm 9$ & 0.01 \\
Body weight (kg) & $61.3 \pm 13.8$ & $62.7 \pm 7.6$ & $\mathrm{NS}$ \\
BMI(kg/m ${ }^{2}$ ) & $22.0 \pm 4.2$ & $21.0 \pm 2.6$ & $\mathrm{NS}$ \\
Glycaemia (mmol/L) & $22.6 \pm 9.4$ & $24.9 \pm 11.2$ & $\mathrm{NS}$ \\
HbA1C (\%) & $12.0 \pm 2.9$ & $12.6 \pm 2.3$ & $\mathrm{NS}$ \\
Weight loss (kg/3months) & $-6.3 \pm 4.8$ & $-7.6 \pm 5.9$ & $\mathrm{NS}$ \\
Intercurrent disease (n) & 6 & 5 & $\mathrm{NS}$ \\
Corticosteroid use(n) & 4 & 2 & NS \\
Sweetened beverages (n) & 5 & 11 & NS \\
Serum C-peptide (nmol/L) & $0.67 \pm 0.73$ & $0.30 \pm 0.16$ & NS \\
Duration of hospitalization (d) & $9.4 \pm 2.3$ & $7.5 \pm 2.5$ & 0.01 \\
Capillary glucose level at discharge (mg/dL) & $146 \pm 47$ & $139 \pm 48$ & NS \\
Daily insulin dose at discharge (U) & $34 \pm 22$ & $51 \pm 27$ & 0.03 \\
Body weight 4 months later (kg) & $65.9 \pm 13.7$ & $70.1 \pm 10.8$ & NS \\
HbA1C 4 months later (\%) & $7.5 \pm 1.9$ & $7.6 \pm 2.0$ & NS \\
\hline
\end{tabular}

\section{Conclusions}

Sixty-one patients were admitted for a new-onset diabetes in our ward during 1996-1997 and 92 during 2008-2009. This $+50 \%$ increase was not due to changing criteria for admission, as we found the same clinical presentation for both time intervals, with similar frank hyperglycaemia and weight loss. The higher rate of admission on 2008-2009 rather reflects the increasing prevalence of diabetes in France, from $2.8 \%$ in 1998 to $4.4 \%$ in 2009 according to a national epidemiological survey [4]. In the Aquitaine area during the same period the prevalence of diabetes also increased from $2.9 \%$ from $3.9 \%$ $[4,5]$. Of note, Barat et al reported a similar $+50 \%$ trend for T1D in children in Aquitaine a few years before [6].

Table 3. Characteristics and outcome of the patients hospitalized for new-onset diabetes, 1996-1997 vs 2008-2009. Patients with negative anti-GAD antibodies.

\begin{tabular}{lccc}
\hline & $\mathbf{1 9 9 6 - 1 9 9 7}$ & $\mathbf{2 0 0 8 - 2 0 0 9}$ & $\mathbf{p}$ \\
\hline $\mathrm{n}$ & 31 & 46 & \\
Men/women & $20 / 11$ & $31 / 15$ & NS \\
Age (yrs) & $48 \pm 16$ & $45 \pm 14$ & NS \\
Body weight (kg) & $66.1 \pm 12.1$ & $78.1 \pm 24.1$ & 0.02 \\
BMI(kg/m ${ }^{2}$ ) & $23.4 \pm 3.2$ & $27.2 \pm 7.2$ & 0.008 \\
Glycaemia (mmol/L) & $17.2 \pm 5.7$ & $17.4 \pm 11.8$ & NS \\
HbA1C (\%) & $11.7 \pm 2.4$ & $12.0 \pm 2.3$ & NS \\
Weight loss (kg/3months) & $-6.4 \pm 4.2$ & $-6.5 \pm 7.3$ & NS \\
Intercurrent disease (n) & 7 & 20 & NS (0.059) \\
Corticosteroid use(n) & 3 & 3 & NS \\
Sweetened beverages (n) & 7 & 20 & NS (0.059) \\
Serum C-peptide (nmol/L) & $1.04 \pm 0.92$ & $1.00 \pm 0.74$ & NS \\
Duration of hospitalization (d) & $9.0 \pm 4.4$ & $7.4 \pm 2.8$ & NS (0.062) \\
Capillary glucose level at discharge & $146 \pm 34$ & $132 \pm 33$ & NS \\
(mg/dL) & $20 \pm 21$ & $29 \pm 25$ & NS \\
Daily insulin dose at discharge (U) & $69.5 \pm 12.8$ & $79.0 \pm 18.4$ & 0.03 \\
Body weight 4 months later (kg) & $7.0 \pm 2.0$ & $7.1 \pm 1.2$ & NS \\
HbA1C 4 months later (\%) & & &
\end{tabular}

Table 4. Characteristics and outcome of the patients hospitalized for new-onset diabetes, 1996-1997 vs 2008-2009. Patients discharged without insulin therapy.

\begin{tabular}{lccc}
\hline & 1996-1997 & 2008-2009 & p \\
\hline $\mathrm{n}$ & $22 / 61$ & $19 / 92$ & 0.04 \\
Men/women & $17 / 5$ & $14 / 5$ & NS \\
Age (yrs) & $54 \pm 15$ & $50 \pm 15$ & NS \\
Body weight (kg) & $76.9 \pm 18.0$ & $93.2 \pm 28.8$ & 0.03 \\
BMI(kg/m $\left.{ }^{2}\right)$ & $26.8 \pm 5.5$ & $31.4 \pm 8.5$ & 0.04 \\
Glycaemia (mmol/L) & $16.2 \pm 5.4$ & $14.4 \pm 7.0$ & NS \\
HbA1C (\%) & $10.8 \pm 2.2$ & $10.6 \pm 2.1$ & NS \\
Weight loss (kg/3months) & $-6.1 \pm 3.6$ & $-4.1 \pm 5.2$ & NS \\
Duration of hospitalization (d) & $8.2 \pm 4.1$ & $6.0 \pm 2.0$ & 0.04 \\
Capillary glucose level at discharge (mg/ & $131 \pm 24$ & $132 \pm 31$ & NS \\
dL) & $79.0 \pm 19.0$ & $90.1 \pm 22.0$ & NS \\
Body weight 4 months later (kg) & $7.0 \pm 2.3$ & $6.9 \pm 1.1$ & NS \\
HbA1C 4 months later (\%) & & &
\end{tabular}


Salandini et al. Journal of Diabetes Research and Clinical Metabolism 2012,

Our main finding is that the patients admitted in our clinical ward for new-onset diabetes are 6 years younger now than twelve years ago, driven by 10 years younger anti-GAD+ patients. This shift to a younger age has been described for childhood T1D in many parts of the world [7,8], including Bordeaux's district [6], but we are not aware of any report of younger adults: lower incidences of T1D in the 15-40 yrs old range as compared to children were even mentioned 10 years ago $[9,10]$. More recent studies have shown a +3 to $+4 \% / y r$ increase of incidence of T1D also in young adults [11,12], but the situation is not known for older ages. The younger age of T1D onset did not associate with higher previous BMI as reported in young children [13] according to the "accelerator hypothesis" [14]. Higher antecedent BMI in younger onset T1D is in fact not an universal finding [15]: Gimenez et al., who searched for this association in the catalan registry for new cases of T1D found a tendency for higher previous BMI only in the youngest ( $<5 y$ rs old), despite this the previous BMI and the age of T1D onset were positively related for the whole 2-25 yrs old population [16], as we found in adults. Lower BMI were also associated with the presence of antiGAD antibodies in 30-49 yrs old adults from registry of the province of Turin [17]. The BMI of our antiGAD+ patients were not higher during 2008-2009 (of note, height 1996-1997: 166 \pm 7 cm vs 2008-2009: $173 \pm 8, p<0.01$ ) so the body weight gain does not seem to explain why our new-onset antiGAD+ patients are younger.

More expected, the new-onset patients with negative antiGAD antibodies were $+12 \mathrm{~kg}$ heavier in 2008-2009 than twelve years before. This dramatic $+1 \mathrm{~kg} / \mathrm{yr}$ increase is more than the $+1 \mathrm{~kg} / 4 \mathrm{yrs}$ reported in the general french adult population (18), reflecting the huge impact of the obesity epidemic for the subjects who are proned to T2D. From the many dietary (or not) factors that contribute to the rise of obesity and T2D, we were especially interested by the increasing frequency of consumption of sugar-containing beverages: repeated reports from various parts of the world indicate that it is associated with a two-fold increase of the incidence of T2D $[19,20,21]$, and according to the evaluation of the french nutrition and health program, the consumption of fruit juice increases in France [22]. Almost half of our polydypsic uncontrolled antiGAD- patients used sugar containing beverages to compensate their polyuria, which surely aggravated their hyperglycaemia. The higher weight of these antiGAD- patients is a therapeutic challenge: due to the intense clinical signs, most of them must be treated by insulin, further gaining weight during the following months as shown in the Table 3. Only $1 / 4$ of the patients can reasonably return home without insulin, with dietary advices, and oral anti diabetic agents, without further gaining weight for the 2008-2009 period, probably because we have intensified our education for physical activity [23]. But these patients are especially heavier and the discharge without insulin becomes less frequent, as shown in the Table 4.

Our third result is the $-25 \%$ reduction of the duration of hospitalization in 2008-2009 as compared with twelve years before, significant and present in every subgroups. This shorter duration (-2.4 days) almost compensates for the higher number of admissions for new-onset diabetes, still accounting for less than $0.5 \%$ of the admissions in our Unit. It was not due to less pronounced clinical presentations: weight loss and $\mathrm{HbA1C}$ were similar. It was not associated with less efficient care: capillary glucose levels at discharge, $\mathrm{HbA1C}$ and weight gain 4 months later did not deteriorate. Whether further reduced hospitalizations will be possible without deteriorating the metabolic results is however uncertain. For example, 4.5 days of hospitalization for initiation of insulin in T2D of 13 yrs duration, allow to decrease $\mathrm{HbA} 1 \mathrm{C}$ from $10.8 \pm 0.2$ to $9.5 \pm 0.2 \%$, far from the objective, and not better than starting as outpatients [24]. Despite the pressure on the French Health Care system to reduce hospitalizations, we hope that they will remain possible: the diagnosis and education (Diet, Self Monitoring of Blood Glucose, Insulin for $75 \%$ of patients and physical activity for some) of such new-onset uncontrolled patients may not be as good with outpatient care, except if specific structures are created, which seems hardly cost-effective for $~ 1$ patient/week in a city like Bordeaux.

Our study has an important limitation: it concerns a specific presentation of adult diabetes, with frank clinical signs and dramatically poor control requiring the hospitalization: they are not representative of the usual adult-onset diabetes. With increasing age, antiGAD become less frequent [25], and the clinical presentation of antiGAD+ patients becomes slower [26], many of these patients may be considered as T2D and initiate insulin without being hospitalized, as proposed by the French Guidelines [27]: this may contribute to the younger age that we observed. We only searched for antiGAD antibodies, other markers of autoimmunity as anti insulin or anti IA2 would have improved our evaluation of autoimmune diabetes, but we do not feel that this would have dramatically changed our results, because antiGAD are the most sensitive [28]. The change of kits for $C$ peptide measurement between the two time intervals is also a limitation, however the $C$ peptide results did not significantly change between 1996-1997 and 2008-2009. The dramatic increase of weight is probably a contributor for the noisy clinical presentation of the antiGAD- patients, not representative of the weight of usual T2D. Although they are not exactly representative, some persistent characteristics of our patients (similar clinical presentation and $\mathrm{HbA1C}$ levels), and the male predominance, as found in most epidemiological reports on diabetes incidence, however suggest that their changes (younger T1D, heavier T2D) are meaningful, as an hospital-emerging part of the diabetes epidemic.

\section{Competing interests}

The authors declare that they have no competing interests.

\section{Authors' Contributions}

VR \& SS conceived of the study, collected data, and wrote 
Salandini et al. Journal of Diabetes Research and Clinical Metabolism 2012, http://www.hoajonline.com/journals/pdf/2050-0866-1-12.pdf

CR, CG and HG collected data and

participated in the study design.

Acknowledgements

We would like to thank Dr. S. Jarman, retired

member of the University Victor Segalen-Bordeaux

2, for revision of the English manuscript.

\section{Publication history}

Editor: Jon S. Odorico, University of Wisconsin - Madison, USA. Received: 24-June-2012 Revised: 08-Aug-2012

Accepted: 10-Sep-2012 Published: 05-Oct-2012

\section{References}

1. American Diabetes Association. Position statement. Hospital admission guideline for diabetes. Diabetes Care 2004; 27 : S103.

2. Karvonen M, Viik-Kajander M, Moltchanova E, Libman I, LaPorte R, Tuomilehto J: Incidence of childhood type 1 diabetes worldwide. Diabetes Mondiale (DiaMond) Project Group. Diabetes Care 2000, 23:1516-1526. | Article | PubMed

3. Variation and trends in incidence of childhood diabetes in Europe. EURODIAB ACE Study Group. Lancet 2000, 355:873-876. | Article | PubMed

4. Fagot-Campagna A, Romon I, Fosse S, Roudier C, Institut de veille sanitaire. Prévalence et incidence du diabète et mortalité liée au diabète en France-Synthèse épidemiologique. 2010 novembre;1-12.

5. Ricardeau P, Weill A, Vallier N, Bourrel R, Fender P, Allemend H. L'épidémiologie du diabète en France métropolitaine. Diabetes \& Metabolism 2000, 26; 11-24.

6. Barat $P$, Valade A, Brosselin P, Alberti C, Maurice-Tison S, Levy-Marchal $C$ : The growing incidence of type 1 diabetes in children: the 17-year French experience in Aquitaine. Diabetes Metab 2008, 34:601-605. | Article | PubMed

7. Vehik K, Hamman RF, Lezotte D, Norris JM, Klingensmith GJ, Dabelea D: Childhood growth and age at diagnosis with Type 1 diabetes in Colorado young people. Diabet Med 2009, 26:961-967. | Article | PubMed

8. Charkaluk ML, Czernichow P, Levy-Marchal C: Incidence data of childhood-onset type I diabetes in France during 1988-1997: the case for a shift toward younger age at onset. Pediatr Res 2002, 52:859-862. | Article | PubMed

9. Pundziute-Licka A, Dahlquist $G$, Nystrom L, Arnqvist H, Bjork E, Blohmé G, Bolinder J, Eriksson JW, Sundkvist G, Ostman J: The incidence of type 1 diabetes has not increased but shifted to a younger age at diagnosis in the 0-34 years group in Sweden 1983-1998. Diabetologia 2002; 45: 783-791. | Article

10. Weets I, De Leeuw IH, Du Caju MV, Rooman R, Keymeulen B, Mathieu C, Rottiers R, Daubresse JC, Rocour-Brumioul D, Pipeleers DG, Gorus FK: The incidence of type 1 diabetes in the age group 0-39 years has not increased in Antwerp (Belgium) between 1989 and 2000: evidence for earlier disease manifestation. Diabetes Care 2002, 25:840-846. | Article I PubMed

11. Lammi N, Blomstedt PA, Moltchanova E, Eriksson JG, Tuomilehto J, Karvonen M: Marked temporal increase in the incidence of type 1 and type 2 diabetes among young adults in Finland. Diabetologia 2008, 51:897-899. | Article | PubMed

12. Wehbe T, Glantz M, Choy H, Glantz L, Cortez S, Akerley W, 3rd, Mills $\mathrm{P}$, Cole $\mathrm{B}$ : Histologic evidence of a radiosensitizing effect of Taxol in patients with astrocytomas. J Neurooncol 1998, 39:245-251. | Article | PubMed

13. Kibirige M, Metcalf B, Renuka R, Wilkin TJ: Testing the accelerator hypothesis: the relationship between body mass and age at diagnosis of type 1 diabetes. Diabetes Care 2003, 26:2865-2870. | Article | PubMed

14. Wilkin TJ: The accelerator hypothesis: weight gain as the missing link between Type I and Type II diabetes. Diabetologia 2001, 44:914-922. I Article | PubMed

15. O'Connell MA, Donath S, Cameron FJ: Major increase in Type 1 diabetes: no support for the Accelerator Hypothesis. Diabet Med 2007, 24:920923. | Article | PubMed

16. Gimenez M, Aguilera E, Castell C, de Lara N, Nicolau J, Conget I: Relationship between BMI and age at diagnosis of type 1 diabetes in a Mediterranean area in the period of 1990-2004. Diabetes Care 2007, 30:15931595. | Article | PubMed

17. Bruno G, Runzo C, Cavallo-Perin P, Merletti F, Rivetti M, Pinach S, Novelli G, Trovati M, Cerutti F, Pagano G: Incidence of type 1 and type 2 diabetes in adults aged $30-49$ years: the population-based registry in the province of Turin, Italy. Diabetes Care 2005, 28:2613-2619. | Article | PubMed

18. Charles MA, Eschwege E, Basdevant A: Monitoring the obesity epidemic in France: the Obepi surveys 1997-2006. Obesity (Silver Spring) 2008, 16:2182-2186. | Article | PubMed Abstract | PubMed Full Text

19. Odegaard AO, Koh WP, Arakawa K, Yu MC, Pereira MA: Soft drink and juice consumption and risk of physician-diagnosed incident type 2 diabetes: the Singapore Chinese Health Study. Am J Epidemiol 2010, 171:701-708. | Article | PubMed Abstract | PubMed Full Text

20. Montonen J, Jarvinen R, Knekt P, Heliovaara M, Reunanen A: Consumption of sweetened beverages and intakes of fructose and glucose predict type 2 diabetes occurrence. J Nutr 2007, 137:1447-1454. | Article | PubMed Abstract | PubMed Full Text

21. Palmer JR, Boggs DA, Krishnan S, Hu FB, Singer M, Rosenberg L: Sugarsweetened beverages and incidence of type $\mathbf{2}$ diabetes mellitus in African American women. Arch Intern Med 2008, 168:1487-1492. | Article | PubMed Abstract | PubMed Full Text

22. Hercberg S. [Effects of the french nutrition and health program on the nutritional status of the population]. Médecine des maladies métaboliques 2009; 3:207-211.

23. Pezzino S, Florenty S, Fagour C, Gin H, Rigalleau V: Remedial actions for the physical inactivity of hospitalized patients with type 2 diabetes. Diabetes Care 2010, 33:1960-1961. | Article | PubMed Abstract | PubMed Full Text

24. Penfornis A, Millot L: Initiating insulin treatment in insulin-requiring type 2 diabetic patients: comparative efficiency and cost of outpatient and inpatient management. INNOV Study Group. Diabetes Metab 1998, 24:137-142. | Article | PubMed

25. Wroblewski M, Gottsater A, Lindgarde F, Fernlund P, Sundkvist G: Gender, autoantibodies, and obesity in newly diagnosed diabetic patients aged 40-75 years. Diabetes Care 1998, 21:250-255. I Article I PubMed

26. Sabbah E, Savola K, Ebeling T, Kulmala P, Vahasalo P, Ilonen J, Salmela PI, Knip M: Genetic, autoimmune, and clinical characteristics of childhoodand adult-onset type 1 diabetes. Diabetes Care 2000, 23:1326-1332. | Article I PubMed

27. Type 2 diabetes treatment: French recommendations for good practice AFSSAPS - HAS.2006. Diabetes Metab 2006, 32:643-648. I PubMed

28. Tiberti C, Buzzetti R, Anastasi E, Dotta F, Vasta M, Petrone A, Cervoni M, Torresi P, Vecci E, Multari G, Di Mario U: Autoantibody negative new onset type 1 diabetic patients lacking high risk HLA alleles in a caucasian population: are these type $1 \mathrm{~b}$ diabetes cases? Diabetes Metab Res Rev 2000, 16:8-14. | Article | PubMed 